\title{
PRÁTICAS ALIMENTARES NA PRIMEIRA INFÂNCIA E EXPERIÊNCIA DE CÁRIE EM CRIANÇAS DE TENRA IDADE
}

\author{
Jéssica Fernandes Eça ${ }^{1}$; Ana Isabel Fonseca Scavuzzi²; Susana Paim dos Santos ${ }^{3}$; Larissa \\ Cartonilho Antunes de Assis ${ }^{4}$
}

1. Bolsista PROBIC/UEFS, Graduanda em Odontologia, Universidade Estadual de Feira de Santana, e-mail: jessica.odonto20@gmail.com

2. Orientador, Departamento de Saúde, Universidade Estadual de Feira de Santana, e-mail: anaisabel.fonseca@outlook.com

3. Doutora em Ciências da Saúde, Departamento de Saúde, Universidade Estadual de Feira de Santana, e-mail: supaim1965@gmail.com

4. Graduanda em Odontologia, Universidade Estadual de Feira de Santana, e-mail: larycartonilho@hotmail.com

PALAVRAS-CHAVE: Cárie Dentária; Hábitos Alimentares; Pré-Escolar

\section{INTRODUÇÃO}

A cárie dentária ainda representa um problema de saúde pública no Brasil, especialmente em crianças jovens. Apesar de se constatar, no último levantamento de Saúde Bucal 2010 realizado pelo Ministério da Saúde um declínio importante da doença nas crianças aos 12 anos de idade, aos 5 anos a redução do índice ceo foi discreta quando comparado ao levantamento de 2003, passando de 2,8 para 2,3. Os dados atuais mostram que o componente cariado aos 05 anos de idade continua preocupante. (BRASIL, 2010)

A ocorrência de cárie precoce na infância têm sido crescentes e os serviços públicos não conseguem absorver essa demanda e realizar as ações de intervenção necessárias, pois o manejo, nesses casos, é muito difícil, requerendo conhecimentos e habilidades específicas. (SANTOS et al.,2016)

Dessa forma, como os hábitos alimentares são adquiridos durante toda a vida, os primeiros anos são um período muito importante para o estabelecimento de hábitos saudáveis que iram promover a saúde do indivíduo. (LANES et al., 2012). A formação de hábitos alimentares saudáveis contribui para a saúde bucal e geral, propiciando uma melhor qualidade de vida para as crianças e satisfação para os pais. (SILVA et al., 2010).

Assim, faz-se necessária a implementanção de programas para auxiliar na intervenção e criar um sistema de vigilância alimentar e nutricional para crianças nessa idade, já que este período é o mais propício para a aquisição de bons hábitos e comportamentos. (MARTINS et a.l,2014)

Entendendo que a exposição a uma dieta desfavorável no início da vida é um fator importante na prevalência de cárie precoce na primeira infância, e os hábitos alimentares são formados, especialmente, nesse período, estimar a associação entre as práticas alimentares nos primeiros anos de vida e a consequência para a criança no futuro, poderia auxiliar nas ações para a prevenção da doença. 
O propósito deste trabalho foi realizar uma revisão de literatura sobre as práticas alimentares na primeira infância e experiência de cárie em crianças de tenra idade.

\section{MATERIAL E MÉTODOS OU METODOLOGIA}

Para a realização desta revisão de literatura foram selecionados artigos científicos sobre práticas alimentares e cárie dentária em pré-escolares todos os artigos sobre o assunto foram incluídos na construção do trabalho.

Consultaram-se as bases de dados especializadas: Google Acadêmico, MEDLINE, Scielo, LILACS e Bireme. Como estratégia de busca, os descritores utilizados foram: cárie dentária, hábitos alimentares e pré-escolar. Os descritores selecionados foram combinados entre si para pesquisa em cada base de dados gerando ao mínimo três combinações não semelhantes.

A realização da busca foi executada sob os seguintes critérios de inclusão: todos os estudos que houvessem sido publicados em língua portuguesa e inglesa entre os anos de 2009 e 2018, que estivessem no formato de artigos científicos e que falassem sobre o tema. Os critérios de exclusão foram: artigos publicados em outros idiomas, que não os incluídos neste estudo, ou não encontrados nas bases de dados selecionadas.

Dos artigos selecionados pelo título, retiraram-se os duplicados e então todos os demais tiveram seus resumos lidos. Dentre os selecionados, todos foram lidos na íntegra, assegurando-se que estes contemplavam todos os critérios de inclusão e os textos completos que não contemplavam o objetivo deste trabalho foram então descartados.

\section{RESULTADOS E/OU DISCUSSÃO}

A partir da busca foram encontrados 482 arquivos, desses apenas 133 estavam disponíveis no formato de artigo científico, após aplicar os critérios de inclusão: préescolar, língua portuguesa e inglesa e ano entre 2009 e 2018, foram encontrados 24 artigos. Sendo que desses, foram descartados os duplicados e os que não contemplavam o objetivo deste trabalho, totalizando 11 artigos, sendo todos lidos na íntegra.

No estudo realizado por (LEAL et al ,2015), as crianças apresentaram consumo de verduras e legumes abaixo da recomendação, enquanto os alimentos do grupo dos óleos e gorduras, bem como do grupo dos açúcares, balas, chocolates e salgadinhos, foram consumidos excessivamente. Corrobando ao estudo (BORTOLINI et al.,2012), em que os resultados apontam a baixa frequência de consumo de alimentos recomendados, importantes para o crescimento e a elevada frequência no consumo de alimentos não recomendados.

De acordo com o estudo realizado por (PARISOTTO et al.,2010) a exposição frequente aos açúcares na forma sólida, a presença de biofilme dentário nos incisivos superiores e o fato da criança levar lanche de casa para a escola foram indicadores de risco expressivos para a cárie precoce da infância na população estudada. Ratificando o que foi encontrado no trabalho de (BIRAL et al.,2013) em que a cárie dentária precoce, a mancha branca e o consumo de carboidratos simples foram claramente observados e associados na população estudada.

No estudo de (TOLONI et al.,2011), os padrões alimentares na infância caracterizados por um maior número de alimentos e bebidas altamente adoçados foram positivamente 
associados à incidência de cárie dentária em idade pré-escolar. No entanto, no estudo realizado por (MARANHÃO et al.,2018) não houve associação às práticas alimentares na fase de lactente nem repercussão posterior sobre o estado nutricional.

A frequência do aleitamento materno pode estar relacionada a outros fatores dietéticos cariogênicos, mas a associação permaneceu estatisticamente significante após ajuste para outras dietas práticas no primeiro ano de vida. Por outro lado, a exposição a açúcares antes dos 12 meses em praticamente todas as crianças no estudo possivelmente contribuiu para o aumento dos níveis Streptococcus mutans, uma variável não investigada no presente estudo e que está fortemente associado à infância. (FELDENS et al., 2010).

Devido à exposição a uma dieta desfavorável no início da vida ser um fator determinante na prevalência de cárie precoce, e por os hábitos alimentares ser formados, nesse período, faz-se necessária à construção de ações voltadas para a adoção de práticas alimentares favoráveis na prevenção da doença. (SANTOS et al.,2016).

\section{CONSIDERAÇÕES FINAIS}

A cárie dentária ainda continua sendo considerada um agravo em saúde bucal na infância, sendo assim necessárias medidas de controle. Dessa forma, os hábitos alimentares cariogênicos estão associados ao surgimento de lesões de cárie em crianças pré-escolares e visto isso, os pais apresentam um papel importante para a incorporação de hábitos saudáveis para seus filhos pequenos.

\section{REFERÊNCIAS}

BIRAL et al. Cárie dentária e práticas alimentares entre crianças de creches do município de São Paulo.Rev. Nutr., Campinas, 26(1):37-48, jan./fev., 2013.

BORTOLINI et al. Consumo alimentar entre crianças brasileiras com idade de 6 a 59 meses. Cad. Saúde Pública, Rio de Janeiro, 28(9):1759-1771, set, 2012.

BRASIL, Ministério da Saúde. Secretaria de Atenção à Saúde. Departamento de Atenção Básica, Coordenação Nacional de Saúde Bucal. Projeto SB Brasil 2010. Condições de saúde bucal da população brasileira. Resultados preliminares. Brasília, DF, 2010.

FELDENS et al. Early Feeding Practices and Severe EarlyChildhood Caries in FourYear-Old Children from Southern Brazil: A Birth Cohort Study. Caries Res, 2010.

LANES et al. Estratégias Lúdicas Para A Construção De Hábitos Alimentares Saudáveis $\mathrm{Na}$ Educação Infantil. Revista Ciências\&Ideias, ISSN: 2176-1477. VOLUME 4, N.1 - JULHO/2012.

LEAL et al. Qualidade da dieta de pré-escolares de 2 a 5 anos residentes na área urbana da cidade de Pelotas, RS. Rev Paul Pediatr. 33(3):310---317,2015.

MARANHÃO et al. Dificuldades Alimentares Em Pré-Escolares, Práticas Alimentares Pregressas E Estado Nutricional Rev Paul Pediatr. 2018;36(1):45-51 
MARTINS et al. Body mass index, dental caries and sugar intake in 2-5 year-old preschoolers. Braz J Oral Sci. 13(3):209-212, 2014.

PARISOTTO et al. A Importância da Prática de Alimentação, Higiene Bucal e FatoresSócio-econômicos na Prevalência da Cárie Precoce da Infância em Pré-escolares de Itatiba-SP. Rev Odontol Bras Central, 2010.

SANTOS et al.. Práticas alimentares e cárie dentária - uma abordagem sobre a primeira infância. REV ASSOC PAUL CIR DENT;70(1):12-8, 2016.

SILVA et al. Alimentação na primeira infância: abordagem para a promoção da saúde bucal. Rev Sul-Bras Odontol.,Oct-Dec;7(4):458-65, 2010.

TOLONI et al. Introdução de alimentos industrializados e de alimentos de uso tradicional na dieta de crianças de creches públicas no município de São Paulo. Rev. Nutr., Campinas, 24(1):61-70, jan./fev., 2011. 